\title{
Removal of Chloramphenicol and Simultaneous Electricity Generation by Using Microbial Fuel Cell Technology
}

\author{
Wei Guo ${ }^{1}$, Mingjiang Geng ${ }^{1}$, Hong Song ${ }^{2}$, Jianhui Sun ${ }^{2, *}$ \\ ${ }^{1}$ Department of Chemistry, Xinxiang Medical University, Xinxiang, Henan 453003, China \\ ${ }^{2}$ School of Environment, Henan Normal University, Key Laboratory for Yellow River and Huaihe, \\ River Water Environmental and Pollution Control Minisitry of Education, Henan Key Laboratory for \\ Environmental Pollution Control, Xinxiang 453007, PR China \\ *E-mail: xiaowei801101@163.com
}

doi: $10.20964 / 2016.06 .42$

Received: 7 March 2016 / Accepted: 3 April 2016 / Published: 4 May 2016

\begin{abstract}
The release of antibiotics into aquatic environments and its related long-term side effects have attracted great attention. As one of the most commonly used antibiotics in China, nitroaromatic antibiotic chloramphenicol (CAP) can be detected in aquatic environments. CAP removal efficiency in the anode chamber of microbial fuel cell (MFC) and the effect of CAP on the electricity output of MFC were studied in this paper. As compared to control experiments including open circuit MFC, no extra carbon source MFC, and abiotic MFC, the removal efficiency of CAP in normal MFC was the most outstanding. However, as the concentration of CAP increased, the removal efficiency is on the decline which is attributed to the CAP load increased. At an initial concentration lower than $30 \mathrm{mg} \mathrm{L}^{-1}$, the electroactive biofilm-based MFC is robust with more than $95 \%$ voltage output maintained, but the

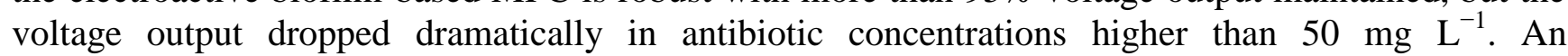
exponential relationship was found between the inhibition ratios of the MFC and the CAP concentrations in the studied concentration range. The findings about the CAP removal and the effects of CAP on the electricity output in two-chambered MFC in this work would have great importance to practical antibiotics wastewater treatment.
\end{abstract}

Keywords: Microbial fuel cell, Chloramphenicol, Bioelectricity generation, Removal

\section{FULL TEXT}

(C) 2016 The Authors. Published by ESG (www.electrochemsci.org). This article is an open access article distributed under the terms and conditions of the Creative Commons Attribution license (http://creativecommons.org/licenses/by/4.0/). 